\title{
Fat content, fatty acid pattern and iron content in livers of turkeys with hepatic lipidosis
}

Christian Visscher $^{1 *} \mathbb{D}$, Lea Middendorf ${ }^{1}$, Ronald Günther ${ }^{2}$, Alexandra Engels ${ }^{3}$, Christof Leibfacher ${ }^{3}$, Henrik Möhle ${ }^{4}$, Kristian Düngelhoef ${ }^{5}$, Stefan Weier ${ }^{6}$, Wolfram Haider $^{7}$ and Dimitri Radko ${ }^{8}$

\begin{abstract}
Background: The so-called "hepatic lipidosis" in turkeys is an acute progressive disease associated with a high mortality rate in a very short time. Dead animals show a massive fatty degeneration of the liver. The cause is still unclear. Previous findings suggest that there may be parallels to human non-alcoholic fatty liver disease. The object of the study was to examine the changes in the fat contents, the fatty acid composition and the iron content in livers of animals, which have died from hepatic lipidosis.
\end{abstract}

Methods: The conspicuous livers $(n=85)$ were collected from 20 flocks where the phenomenon of massive increased animal losses accompanied by marked macroscopically visible pathological liver steatosis suddenly occurred. For comparison and as a reference, livers $(n=16)$ of two healthy flocks were taken. Healthy and diseased flocks were fed identical diets concerning official nutrient recommendations and were operating under standardized, comparable conventional conditions.

Results: Compared to livers of healthy animals, in the livers of turkeys died from hepatic lipidosis there were found massively increased fat levels (130 \pm 33.2 vs. $324 \pm 101 \mathrm{~g} / \mathrm{kg}$ dry matter-DM). In all fatty livers, different fatty acids concentrations were present in significantly increased concentrations compared to controls (palmitic acid: $104 \mathrm{~g} / \mathrm{kg} \mathrm{DM},+345 \%$; palmitoleic acid: $18.0 \mathrm{~g} / \mathrm{kg} \mathrm{DM},+570 \%$; oleic acid: $115 \mathrm{~g} / \mathrm{kg}$ DM, $+437 \%)$. Fatty acids concentrations relevant for liver metabolism and inflammation were significantly reduced (arachidonic acid: $2.92 \mathrm{~g} / \mathrm{kg} \mathrm{DM},-66.6 \%$; eicosapentaenoic acid: $0.141 \mathrm{~g} / \mathrm{kg} \mathrm{DM},-78.3 \%$; docosahexaenoic acid: $0.227 \mathrm{~g} / \mathrm{kg} \mathrm{DM},-90.4 \%)$. The ratio of certain fatty acids to one another between control and case livers changed analogously to liver diseases in humans (e.g.: C18:0/C16:0 - 0.913 against 0. 311; C16:1n7/C16:0 - 0.090 against 0.165; C18:1/C18:0 - 0.938 against 4.03). The iron content in the liver tissue also increased massively (271 \pm 51.5 vs $712 \pm 214 \mathrm{mg} / \mathrm{kg} \mathrm{DM}$ ).

Conclusion: The hepatic lipidosis has a massive impact on the lipid content, the lipid composition and the iron content in the liver. The character of the metabolic disorder includes parallels to the non-alcoholic steatohepatitis in humans.

Keywords: Hepatic lipidosis, Hepatic fatty acid pattern, Iron, Steatohepatitis

\footnotetext{
* Correspondence: Christian.visscher@tiho-hannover.de

${ }^{1}$ Institute for Animal Nutrition, University of Veterinary Medicine Hannover,

Foundation, Bischofsholer Damm 15, D-30173 Hannover, Germany

Full list of author information is available at the end of the article
} 


\section{Background}

On turkey farms, a devastating disease associated with massive changes in hepatic tissue has already been described in literature for more than 20 years [1]. The disease is associated with sudden death in up to $15 \%$ of animals in flocks without previous clinical signs of illness $[1,2]$. In practice, a certain impaired blood coagulation is also described. The typical pathological changes in dead animals focus on the liver [2]. Fat accumulation in hepatocytes, leading to the formation of large vacuoles in the cytoplasm, fatty degeneration, severe and multifocal, acute, hemorrhagic, necrotising hepatitis with eosinophilic intranuclear inclusions are typical signs in animals which died from hepatic lipidosis [2, 3]. In severe cases signet ring cells occur [4]. The etiology and pathogenesis is still unclear. Both metabolic and infectious causes are discussed $[1,2]$. In human medicine a disease has been occurring for years with similar pathological changes. The nonalcoholic fatty liver disease (NAFLD) in the harmless form as simple steatosis (SS) or in the more serious variant as nonalcoholic steatohepatitis (NASH) is increasingly recognized as the hepatic manifestation of insulin resistance and the systemic complex known as metabolic syndrome [5].

Unlike in humans, where a standardized and validated system for the histological evaluation of the fatty liver disease exists [5], these methods are missing in poultry. Nevertheless, to gain a better understanding of the pathogenesis of the so-called "hepatic lipidosis" in turkeys the fatty acid composition is of interest. The ratios of destinct fatty acids in the liver are correlated to the steatosis score in humans, others are associated with the lobular inflammation score [6]. Additionally, the iron content in liver samples is important in order to be able to assess the involvement of infections or kind of metabolic disorders [7].

The object of the study was to examine the changes in the fat contents, the fatty acid composition and the iron content in livers of animals, which have died from hepatic lipidosis to get a step closer to the triggers of this disease.

\section{Methods}

The study took place in cooperation with German poultry veterinarians. Only veterinarians have been addressed who had already observed the phenomenon of hepatic lipidosis in turkeys during the previous years. Therefore, these persons were optimally trained in clinical diagnosis. Only samples from clinically apparent cases were obtained when it was ensured that the conditions of feeding and the diets corresponded to the conventional standard. Thus, the conditions were comparable between all farms and did not differ from non-affected flocks. In case of a hepatic lipidosis in fattening turkey flocks, livers were collected from four to five dead animals and used for further investigations. Sample collection was done in the pathology unit of the specific veterinary practices. So this study was not based on an animal experiment requiring a notification or an approval according to the Animal Protection Act. Interventions were carried out only on dead or slaughtered animals.

From January 2015 to April 2016, a total of 85 samples were collected from 20 different diseased flocks. For comparison, samples $(n=16)$ from healthy slaughtered turkeys from two non-affected flocks were collected.

\section{Animals and feeding}

In the investigations exclusively commercial turkeys from line "B.U.T. Big 6" were included. In eighteen out of twenty affected flocks, only female animals were kept and in two only male turkeys. The farm size differed between 10,000-30,000 animals each. Animals were fed a commercial complete diet. The feeding programme consisted as usual of several phases, which were adapted to the energy and nutrients demands with regard to the age of the birds (Table 1). The individual farms were supplied by several feed mills. In the majority of cases, the phenomenon occurred during the fattening period at the time of the fourth and fifth feeding phase. These diets no longer contained coccidiostats. All animals were fed ad libitum.

\section{Sample collection}

At the time of illness the animals were on average about 90-95 days of age. The extent of losses due to the illness varied. Between $1.5 \%$ and $10 \%$ total losses were due to hepatic lipidosis. Within a few hours four to five animals that had died suddenly were taken randomly and transferred immediately to pathology of each veterinary practice. Here the removal of the liver took place under sterile conditions. A systematic macroscopic assessment as in humans [5] was not possible because in each practice different investigators took the samples. Whole liver samples were taken (Fig. 1, b1), stored in plastic screw vials (500 mL, Sarstedt, Germany) and sent on ice immediately to the laboratory.

\section{Chemical analysis}

Samples of all diets were analysed by standardized laboratory methods according to the VDLUFA [8]. The analyses were always performed in duplicate. The dry matter content was determined by drying to the weight constancy at $103{ }^{\circ} \mathrm{C}$. The crude ash was analysed by means of incineration in the muffle furnace at $600{ }^{\circ} \mathrm{C}$ for $6 \mathrm{~h}$. The total nitrogen content was determined by means of the analyser Vario $\operatorname{Max}^{\oplus}$ (Elementar, Hanau, Germany), which operates according to the principle of a catalytic tube combustion (DUMAS combustion method). The molecular nitrogen formed by reduction from nitric oxide was detected by a thermal conductivity detector and the nitrogen content 
Table 1 Nutrient composition of the case diets at time of outbreak of hepatic lipidosis in flocks

\begin{tabular}{|c|c|c|c|c|c|}
\hline \multirow[t]{2}{*}{ Item } & \multicolumn{2}{|c|}{ Nutrient content $\left(\mathrm{g} / \mathrm{kg}\right.$ diet) ${ }^{\mathrm{a}}$} & \multirow[t]{2}{*}{ Item } & \multicolumn{2}{|c|}{ Nutrient content (g/kg diet) } \\
\hline & Mean & SD & & Mean & SD \\
\hline \multirow[t]{2}{*}{ ME (MJ/kg diet) } & 12.4 & 0.20 & Arginine & 11.0 & 1.39 \\
\hline & & & Cysteine & 2.94 & 0.35 \\
\hline Crude ash & 45.8 & 7.58 & Isoleucine & 6.89 & 0.76 \\
\hline Crude fat & 64.0 & 7.10 & Leucine & 13.7 & 1.41 \\
\hline Crude fibre & 29.1 & 3.65 & Lysine & 11.4 & 0.95 \\
\hline Crude protein & 177 & 15.0 & Methionine ${ }^{b}$ & 3.39 & 1.16 \\
\hline Starch & 414 & 15.6 & Phenylalanine & 8.36 & 1.15 \\
\hline Sugar & 37.9 & 4.27 & Threonine & 6.56 & 0.97 \\
\hline Palmitic acid & 13.8 & 6.79 & Valine & 8.12 & 0.70 \\
\hline Palmitoleic acid & 0.11 & 0.02 & Alanine & 7.85 & 0.81 \\
\hline Margaric acid & 0.06 & 0.01 & Aspartic acid & 13.6 & 2.56 \\
\hline Stearic acid & 1.84 & 0.49 & Glutamic acid & 36.5 & 2.35 \\
\hline Oleic acid & 18.7 & 2.47 & Glycine & 7.56 & 0.62 \\
\hline Linoleic acid & 23.5 & 1.58 & Histidin & 4.58 & 0.36 \\
\hline a-Linolenic acid & 1.67 & 0.19 & Proline & 12.6 & 0.74 \\
\hline Arachidic acid & 0.24 & 0.03 & Serine & 8.93 & 1.07 \\
\hline Iron (mg/kg diet) & 226 & 42.8 & Tyrosine & 6.16 & 0.75 \\
\hline
\end{tabular}

Nutrient content $=$ amounts of raw nutrients, fatty acids, iron and amino acids

${ }^{\mathrm{a}}$ In total eight diets were analysed; ${ }^{\mathrm{b}}$ Only DL-methionine

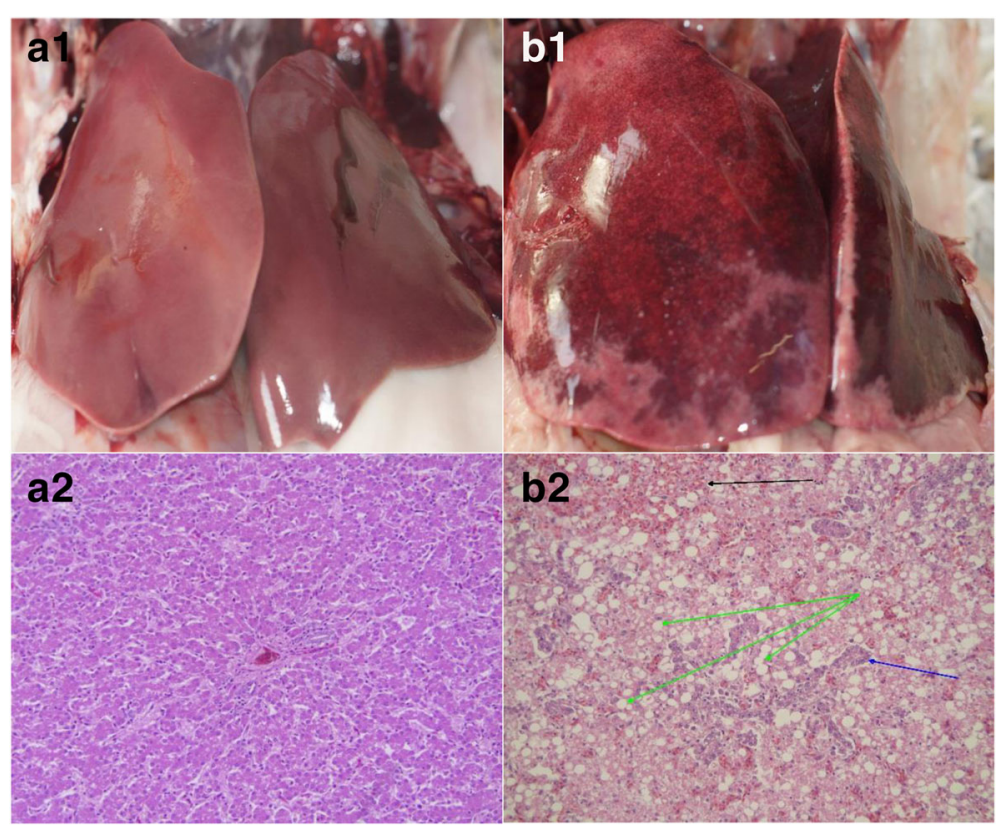

Fig. 1 Typical macroscopic image of livers from healthy turkeys (a1) and deceased turkeys with hepatic lipidosis (b1) and histological pictures of livers from healthy turkeys $(a 2, \mathrm{HE}-$ staining, $\times 20)$ and deceased turkeys with hepatic lipidosis $(b 2, \mathrm{HE}-$ staining, $\times 20 ;$ black arrow: dilated sinusoids filled with blood; blue arrow: biliary duct proliferates; green arrows: liver cells with fat vacuoles) 
was calculated by the device software. The crude protein content of the sample was calculated by multiplication with a constant factor of 6.25. The dietary content of crude fibre was determined after washing in diluted acids and alkalis by established methods. The determination of starch contents was carried out polarimetrically (Polatronic E, Schmidt und Haensch GmbH \& Co., Berlin, Germany). The sugar content was analysed according to Luff-Schoorl by titration with sodium thiosulphate. Amino acids in feed samples were determined by ion-exchange chromatography (AA analyser LC 3000, Biotronic, Maintal, Germany). Results were evaluated according to established methods [9]. In feed and liver samples the crude fat content was determined after acid hydrolysis in the Soxhlet apparatus. For the calculation of nutrient concentration in the fat-free DM, the absolute fat content was subtracted from the DM content of a sample. The mineral content was analysed in accordance with the official methods [8] by atomic absorption spectrometry (Unicam Solaar 116, from Thermo, Dreieich, Germany). The determination of levels of long chain fatty acids in liver samples was carried out using established methods [10]. Exactly $200 \mathrm{mg}$ of liver tissue was placed in a glass tube. A methanol-hexane-tridecanoicacid mixture was utilised as standard. Subsequently, acetyl chloride was added and the sample was heated, followed by the addition of potassium chloride solution. The measurement was carried out by gaschromatography (GC TRACE 1300, ThermoScientific ${ }^{\circ}$, Dreieich, Germany; SP-2560 Column, Supelco, Bellefonte, USA; carrier gas: nitrogen) after centrifugation with the superior hexane phase.

\section{Statistical analysis}

The statistical analysis of the data was performed using the Statistical Analysis System for Windows, the SAS Enterprise Guide ${ }^{\bullet}$ version 7.1 (SAS Institute Inc. Cary, USA). First, for statistical analysis normal distribution of data was verified. For that residuals of the data of single parameters were compared with the normal distribution. After that one-way ANOVA was calculated in the presence of a normal distribution (Ryan Einot-Gabriel-Welsch statistics). In non-normally distributed data, the Wilcoxon test was carried out.

For the purpose of evaluating parameters like iron content and certain fatty acids concentrations in liver, fatty acid classes (fl) for liver tissue were defined according to the total amount of long chain fatty acids analysed in dry matter (DM) of liver tissue: $\mathrm{fl} 1: \leq 200 \mathrm{~g} / \mathrm{kg} \mathrm{DM}$; fl 2: > 200-250 g/kg DM; fl 3: > 250-300 g/kg DM; fl 4: > 300-350 g/kg DM; fl 5: > 350-400 g/kg DM; fl 6: > 400-450 g/kg DM; fl 7: > $450 \mathrm{~g} / \mathrm{kg}$ DM. This was followed by a comparative analysis of each parameter with one-way ANOVA (Ryan Einot-Gabriel-Welsch statistics).

For the correlation analysis of normal distributed data the correlation coefficient of Pearson was used. In nonnormally distributed residuals the rank correlation coefficient according to Spearman was calculated. All statistical tests were two-sided; a $P$-value $<0.05$ was considered significant.

\section{Results}

Until there was an outbreak of the disease, the animal losses on the farms amounted to normal values. The complete diets used on the farms completely matched usual turkey diets. Performance level in flocks was high up to the outbreak of illness and exceeded the performance goals of the genetic line.

\section{Fat content and fatty acid composition of liver tissue}

To compare the liver composition of healthy and affected animals, a total of 101 liver samples from 22 farms were tested. These were 16 livers from healthy animals and 85 livers from affected animals from flocks suffering from hepatic lipidosis. The fat content in the liver of affected animals was approximately three times higher than the content in the livers of healthy birds, thus significantly increased (control: $123 \pm$ 36.6; case: $345 \pm 103 \mathrm{~g} / \mathrm{kg} \mathrm{DM}$ ). The sum of the individual fatty acids changed in an identical manner (control: $130 \pm 33.2$; case: $324 \pm 101 \mathrm{~g} / \mathrm{kg} \mathrm{DM}$ ).

With regard to the absolute content of the individual fatty acids significant differences between the levels in control livers and case-livers were seen. Concerning long chain fatty acids (Table 2) significant differences were only missing for stearic acid.

The absolute contents of arachidonic acid, eicosapentaenoic acid and docosahexaenoic acid were significantly lower in livers of animals that died from hepatic lipidosis. The content of other fatty acids was higher in affected animals. With respect to the relative proportions of the corresponding fatty acids significant shifts were revealed. While the relative proportion of margaric acid and gadoleic acid remained unchanged, the amount of stearic acid, linoleic acid, arachidonic acid, eicosapentaenoic acid and docosahexaenoic acid, however, was significantly lower. The share of other fatty acids increased.

The comparison at fatty acid category level (Table 3) shows for the fatty acids with the highest proportions in the liver a continuous increase in saturated and monounsaturated fatty acids at higher fat content. In the case of palmitic acid, palmitoleic acid and oleic acid, it was significantly higher in this category. For linoleic acid and $\alpha$ linolenic acid the second highest category of fat was associated with the highest fatty acid content. In the highest category, fatty acid values were significantly smaller again. 
Table 2 Comparative overview of the content, the relative changes in the fatty acid concentration in the liver

\begin{tabular}{|c|c|c|c|c|c|}
\hline \multirow[t]{3}{*}{ Item $^{c}$} & \multirow{2}{*}{\multicolumn{2}{|c|}{$\begin{array}{l}\text { Content } \\
{[\mathrm{g} / \mathrm{kg} \text { liver } \mathrm{DM} \pm \mathrm{SD}]}\end{array}$}} & \multirow{3}{*}{$\begin{array}{l}\text { Relation }^{d} \\
\text { [\% of control] } \\
\text { Case }\end{array}$} & \multirow{2}{*}{\multicolumn{2}{|c|}{$\begin{array}{l}\text { Relative share }^{e} \\
{[\% \pm S D]}\end{array}$}} \\
\hline & & & & & \\
\hline & Control & Case & & Control & Case \\
\hline Myristic acid C14:0 & $0.411^{b} \pm 0.138$ & $1.93^{\mathrm{a}} \pm 0.936$ & $469 \pm 228$ & $0.328^{b} \pm 0.124$ & $0.582^{\mathrm{a}} \pm 0.192$ \\
\hline Trans-Myristic acid C14:1 & $0.070^{b} \pm 0.070$ & $0.350^{a} \pm 0.208$ & $504 \pm 299$ & $0.045^{b} \pm 0.040$ & $0.103^{a} \pm 0.05 c$ \\
\hline Palmitic acid C16:0 & $30.2^{\mathrm{b}} \pm 8.41$ & $104^{a} \pm 32.6$ & $345 \pm 108$ & $23.3^{b} \pm 1.29$ & $32.1^{\mathrm{a}} \pm 3.09$ \\
\hline Palmitoleic acid C16:1 & $3.17^{b} \pm 2.80$ & $18.0^{a} \pm 9.62$ & $570 \pm 304$ & $2.08^{b} \pm 1.67$ & $5.27^{\mathrm{a}} \pm 2.01$ \\
\hline Margaric acid C17:0 & $0.244^{b} \pm 0.103$ & $0.495^{a} \pm 0.208$ & $202 \pm 85.2$ & $0.215^{a} \pm 0.139$ & $0.169^{\mathrm{a}} \pm 0.135$ \\
\hline Stearic acid C18:0 & $26.5^{\mathrm{a}} \pm 3.22$ & $28.3^{\mathrm{a}} \pm 5.47$ & $107 \pm 20.7$ & $21.1^{\mathrm{a}} \pm 3.13$ & $9.79^{b} \pm 4.13$ \\
\hline Elaidic acid C18:1n9t & $0.395^{b} \pm 0.199$ & $1.27^{\mathrm{a}} \pm 0.516$ & $320 \pm 131$ & $0.287^{b} \pm 0.109$ & $0.389^{a} \pm 0.123$ \\
\hline Oleic acid C18:1n9c & $26.4^{b} \pm 18.8$ & $115^{\mathrm{a}} \pm 43.9$ & $437 \pm 166$ & $18.1^{b} \pm 10.1$ & $34.3^{\mathrm{a}} \pm 7.02$ \\
\hline Linoleic acid C18:2n6c & $29.3^{b} \pm 3.54$ & $45.9^{a} \pm 20.9$ & $157 \pm 71.2$ & $23.5^{\mathrm{a}} \pm 4.26$ & $14.4^{\mathrm{b}} \pm 4.55$ \\
\hline a-Linolenic acid C18:3n3 & $0.547^{b} \pm 0.180$ & $2.61^{a} \pm 1.68$ & $478 \pm 307$ & $0.418^{b} \pm 0.068$ & $0.755^{\mathrm{a}} \pm 0.387$ \\
\hline Gadoleic acid C20:1 & $0.294^{b} \pm 0.112$ & $0.624^{a} \pm 0.298$ & $212 \pm 101$ & $0.220^{\mathrm{a}} \pm 0.047$ & $0.193^{\mathrm{a}} \pm 0.081$ \\
\hline Arachidonic acid C20:4n6 & $8.75^{\mathrm{a}} \pm 1.67$ & $2.92^{b} \pm 2.08$ & $33.4 \pm 23.8$ & $7.17^{\mathrm{a}} \pm 2.48$ & $1.37^{b} \pm 2.62$ \\
\hline Eicosapentaenoic acid C20:5n3 & $0.651^{\mathrm{a}} \pm 0.449$ & $0.141^{b} \pm 0.122$ & $21.7 \pm 18.8$ & $0.566^{\mathrm{a}} \pm 0.512$ & $0.048^{\mathrm{b}} \pm 0.05$ \\
\hline DHA Docosahexaenoic acid C22:6n3 & $2.37^{\mathrm{a}} \pm 2.96$ & $0.227^{b} \pm 0.254$ & $9.59 \pm 10.8$ & $2.33^{\mathrm{a}} \pm 3.15$ & $0.120^{b} \pm 0.34$ \\
\hline
\end{tabular}

${ }^{c}$ Medium and long chain fatty acids in concentrations $>0.5 \mathrm{~g} / \mathrm{kg}$ DM were considered in the comparison

${ }^{d}$ In animals with hepatic lipidosis in relation to the fatty acid concentrations in the livers of healthy animals (basis for calculation $=100 \%$ )

e Percentage distribution of medium and long chain fatty acids (FA) in liver tissue of healthy $(n=16)$ and deceased ( $n=85)$ animals from conspicuous flocks with hepatic lipidosis

${ }^{a, b}$ Values within a row concerning object of investigation with different superscripts differ significantly at $P<0.05$

Table 3 Long chain fatty acids and fatty acid ratios related to metabolism pathways [1] in liver tissue

\begin{tabular}{|c|c|c|c|c|c|c|c|c|c|c|c|c|c|c|c|c|c|}
\hline \multicolumn{2}{|l|}{ Item } & \multirow{2}{*}{\multicolumn{2}{|c|}{$\begin{array}{l}\text { Control } \\
(n=16)\end{array}$}} & \multicolumn{14}{|l|}{ Case } \\
\hline \multirow[t]{2}{*}{ Acid } & \multirow[t]{2}{*}{ ( } & & & \multicolumn{2}{|c|}{$f \mid 1(n=8)$} & \multicolumn{2}{|c|}{$\mathrm{fl} 2(n=10)$} & \multicolumn{2}{|c|}{$\mathrm{fl} 3(n=13)$} & \multicolumn{2}{|c|}{$\mathrm{fl}(n=10)$} & \multicolumn{2}{|c|}{$\mathrm{fl}(n=17)$} & \multicolumn{2}{|c|}{$f \mid 6(n=12)$} & \multicolumn{2}{|c|}{$f l 7(n=9)$} \\
\hline & & Mean & SD & Mean & SD & Mean & SD & Mean & SD & Mean & SD & Mean & SD & Mean & SD & Mean & SD \\
\hline Palmitic & $\mathrm{g} / \mathrm{kg} \mathrm{DM}$ & $30.2^{e}$ & 8.41 & $36.1^{\mathrm{e}}$ & 21.5 & $77.6^{d}$ & 8.39 & $90.9^{c}$ & 6.33 & $102^{c}$ & 8.98 & $123^{b}$ & 12.2 & $128^{b}$ & 10.8 & $151^{a}$ & 9.40 \\
\hline Palmitoleic & & $3.17^{c}$ & 2.80 & $5.06^{c}$ & 5.01 & $8.60^{c}$ & 3.35 & $16.6^{\mathrm{b}}$ & 3.55 & $16.3^{b}$ & 4.74 & $21.0^{\mathrm{b}}$ & 6.47 & $22.5^{\mathrm{b}}$ & 8.08 & $33.6^{\mathrm{a}}$ & 9.24 \\
\hline Stearic & & $26.5^{c d}$ & 3.22 & $20.0^{e}$ & 2.84 & $25.6^{d}$ & 3.08 & $26.1^{\mathrm{cd}}$ & 3.02 & $28.2^{\mathrm{bcd}}$ & 3.82 & $30.7^{a b c}$ & 4.89 & $31.6^{\mathrm{ab}}$ & 4.84 & $33.3^{\mathrm{a}}$ & 6.14 \\
\hline Oleic & & $26.4^{e}$ & 18.8 & $27.1^{\mathrm{e}}$ & 24.6 & $67.7^{d}$ & 11.2 & $104^{c}$ & 12.2 & $117^{c}$ & 14.5 & $136^{\mathrm{b}}$ & 13.4 & $146^{\mathrm{b}}$ & 17.9 & $179^{a}$ & 19.6 \\
\hline Linoleic & & $29.3^{e}$ & 3.54 & $16.4^{f}$ & 3.50 & $33.0^{\text {de }}$ & 8.12 & $32.8^{\text {de }}$ & 11.0 & $45.3^{\mathrm{cd}}$ & 12.2 & $50.1^{b c}$ & 14.4 & $75.1^{a}$ & 13.9 & $59.7^{b}$ & 21.3 \\
\hline a-linoleic & & $0.55^{d}$ & 0.18 & $0.28^{d}$ & 0.17 & $1.78 \mathrm{c}$ & 0.73 & $1.60 c$ & 0.95 & $2.67 \mathrm{bc}$ & 1.08 & $2.62 b c$ & 1.08 & $5.13 a$ & 1.31 & $3.58 \mathrm{~b}$ & 1.47 \\
\hline Arachidonic & $\mathrm{g} / \mathrm{kg} \mathrm{DM}$ & $8.75^{\mathrm{a}}$ & 1.67 & $5.52^{\mathrm{b}}$ & 4.75 & $2.89^{c}$ & 1.76 & $2.33^{c}$ & 1.37 & $2.99^{c}$ & 1.29 & $2.17^{c}$ & 1.33 & $3.24^{c}$ & 1.14 & $2.35^{c}$ & 1.36 \\
\hline Eicosapentaenoic & & $0.65^{\mathrm{a}}$ & 0.45 & $0.11^{\mathrm{b}}$ & 0.12 & $0.10^{\mathrm{b}}$ & 0.06 & $0.09^{\mathrm{b}}$ & 0.09 & $0.14^{b}$ & 0.08 & $0.15^{\mathrm{b}}$ & 0.15 & $0.20^{\mathrm{b}}$ & 0.13 & $0.20^{\mathrm{b}}$ & 0.18 \\
\hline Docosahexanoic & & $2.37^{\mathrm{a}}$ & 2.96 & $0.59^{b}$ & 0.67 & $0.19^{\mathrm{b}}$ & 0.11 & $0.12^{\mathrm{b}}$ & 0.06 & $0.16^{\mathrm{b}}$ & 0.10 & $0.21^{b}$ & 0.11 & $0.23^{b}$ & 0.16 & $0.25^{b}$ & 0.19 \\
\hline \multicolumn{18}{|l|}{ Ratio } \\
\hline C18:0/C16:0 [1] & $\mathrm{g} / \mathrm{kg} \mathrm{DM}$ & $0.91^{\mathrm{a}}$ & 0.15 & $0.71^{b}$ & 0.31 & $0.33^{c}$ & 0.04 & $0.29^{c}$ & 0.04 & $0.28^{c}$ & 0.04 & $0.25^{c}$ & 0.04 & $0.25^{c}$ & 0.04 & $0.22^{c}$ & 0.03 \\
\hline $\mathrm{C} 16: 1 \mathrm{n} 7 / \mathrm{C} 16: 0[1]$ & & $0.09^{c}$ & 0.07 & $0.11^{b c}$ & 0.10 & $0.11^{b c}$ & 0.04 & $0.18^{\mathrm{ab}}$ & 0.04 & $0.16^{\mathrm{ab}}$ & 0.05 & $0.17^{\mathrm{ab}}$ & 0.06 & $0.17^{\mathrm{ab}}$ & 0.06 & $0.22^{\mathrm{a}}$ & 0.07 \\
\hline C18:1n9/C16:0 [1] & & $0.94^{d}$ & 0.62 & $1.32^{d}$ & 1.17 & $2.69^{c}$ & 0.63 & $4.06^{b}$ & 0.67 & $4.20^{\mathrm{b}}$ & 0.62 & $4.57^{\mathrm{ab}}$ & 1.08 & $4.74^{\mathrm{ab}}$ & 1.07 & $5.59^{\mathrm{a}}$ & 1.36 \\
\hline$n-6 / n-3[1]$ & & $23.5^{\mathrm{ab}}$ & 12.5 & $30.3^{\mathrm{a}}$ & 9.68 & $20.0^{\mathrm{b}}$ & 5.90 & $23.8^{\mathrm{ab}}$ & 10.3 & $18.4^{\mathrm{b}}$ & 4.66 & $19.3^{b}$ & 4.22 & $15.0^{\mathrm{b}}$ & 1.75 & $17.0^{\mathrm{b}}$ & 4.01 \\
\hline
\end{tabular}

Fat level $1=\mathrm{fl} 1: \leq 200 \mathrm{~g} / \mathrm{kg}$ DM; Fat level $2=\mathrm{fl} 2:>200-250 \mathrm{~g} / \mathrm{kg} \mathrm{DM}$; Fat level $3=\mathrm{fl} 3:>250-300 \mathrm{~g} / \mathrm{kg} \mathrm{DM}$; Fat level $4=\mathrm{fl} 4:>300-350 \mathrm{~g} / \mathrm{kg}$ DM; Fat level $5=\mathrm{fl}$ 5: > 350-400 g/kg DM; Fat level 6 = fl 6:> 400-450 g/kg DM; Fat level $7=\mathrm{fl} 7:>450 \mathrm{~g} / \mathrm{kg} \mathrm{DM}$

$\mathrm{a}, \mathrm{b}, \mathrm{c}, \mathrm{d}, \mathrm{e}$ Values within a row with different superscripts differ significantly at $P<0.05$ 
The contents of the n- 6 fatty acid arachidonic acid and the n-3 fatty acids eicosapentaenoic acid and docosahexaenoic acid were significantly lower in the livers of animals with hepatic lipidosis (Table 3) but within the different fat level categories there were no differences in livers of diseased animals for the eicosapentaenoic acid and docosahexaenoic acid. The content of arachidonic acid decreased gradually. Here, the category fl 1 had, nevertheless, still significantly higher arachidonic acid content than the following fatty acid categories.

The ratio of $\mathrm{C} 18: 1$ to $\mathrm{C} 18: 0$, equivalent to the activity of $\Delta 9$ desaturase, was significantly increased in the livers of affected animals (Table 4). Both, the n-6 - and n-3 pathway indicated significantly lower values in the case group. The ratio of $n-6$ to $n-3$ fatty acids according to [11] was not significantly different. The ratio of stearic acid to palmitic acid as well as the ratio of palmitoleic acid to palmitic acid and oleic acid to palmitic acid were significantly lower in affected animals. The ratio n-6 to n-3 according [6] showed no significant differences.

The comparison of fatty acid ratios at fat category level (Table 3) shows that the ratio of C18:0 to C16:0 was significantly lower in the liver of animals that had died from hepatic lipidosis. In deceased animals, livers with a fat content greater than $200 \mathrm{~g}$ again had a significantly lower ratio. The ratio of $\mathrm{C} 16: 1 \mathrm{n} 7$ to $\mathrm{C} 16: 0$ showed an opposite trend. In the control group, the ratio was 0.09 , and thus significantly lower than in deceased animals. The significantly highest ratio was found in animals with a liver fat content of $>450 \mathrm{~g}$ (Table 3 ). Here the ratio was 0.22 .

The ratio of $\mathrm{C} 18: 1 \mathrm{n} 9$ to $\mathrm{C} 16: 0$ was significantly lower in livers of healthy animals as well as in affected animals whose livers had a fat content of less than $200 \mathrm{~g}$ (c: $0.938 \pm 0.616$; fl $1: 1.33 \pm 1.17$ ). In relation to that, dead animals with higher fat content in the liver had significantly higher ratios (fl 2: $2.69 \pm 0.634$; fl 3: $4.06 \pm$ 0.672 ; fl $4: 4.20 \pm 0.621$; fl $5: 4.57 \pm 1.08$; fl $6: 4.74 \pm$ 1.07; fl 7: $5.59 \pm 1.36)$.
The ratio of n-6 to n-3 fatty acids was significantly highest in the group of case animals and simultaneously still had a liver fat content of $<200 \mathrm{~g}$ (fl 1: $30.3 \pm 9.68$ ) compared to the levels in livers of other fatty acid categories. In relation to the healthy animals, there were no significant differences (c: $23.5 \pm 12.5$ ).

There was a very strong Spearman rank correlation coefficient between the sum of the fatty acids in the liver tissue and the levels of palmitic acid (0.95) and the content of oleic acid (0.93, Table 5). There was also a very strong correlation coefficient between trans-myristic acid and palmitoleic acid, palmitic acid and oleic acid, palmitoleic acid and oleic acid and linoleic acid and alpha-linolenic acid, respectively.

A strong negative correlation was found between the level of fatty acids in the liver and the iron content, the contents of myristic acid, trans-myristic acid, palmitoleic acid, stearic acid, oleic acid, linoleic acid, alpha-linolenic acid and gadoleic acid in the liver. The contents of myristic acid and trans-myristic acid, palmitic acid, margaric acid, stearic acid, elaidic acid, linoleic acid and gadoleic strongly correlated as did the contents of trans-myristic acid and oleic acid. The levels of palmitic acid and palmitoleic acid, margarinic, stearic acid, oleic acid, linoleic acid, and gadoleic acid also highly correlated as did oleic acid and gadoleic acid. There existed a strong Pearson correlation between heptadecenoic acid and stearic acid, heptadecenoic acid and elaidic acid and between stearic and elaidic acid (Table 5).

\section{Iron content in the liver tissue}

The iron content in the liver tissue also increased massively (control: $271 \pm 51.5$; case: $712 \pm 214 \mathrm{~g} / \mathrm{kg}$ DM) as well as the iron content in fat free liver tissue (control: $311 \pm 64.7$; case: $1084 \pm 249$ g/kg DM). Therefore, calculated on the fat-free basis it was more than three times higher.

The statistical analysis of the iron content versus fat classes in the liver tissue showed that the iron content

Table 4 Comparative overview of the different fatty acid ratios according to different authors [6, 11]

\begin{tabular}{|c|c|c|}
\hline Ratio & $\begin{array}{l}\text { Control }(n=16) \\
\text { Mean } \pm \text { SD }\end{array}$ & $\begin{array}{l}\text { Case }(n=85) \\
\text { Mean } \pm \text { SD }\end{array}$ \\
\hline " $\Delta 9$ desaturase" [11] (C18:1/C18:0) & $0.938^{b} \pm 0.616$ & $4.03^{\mathrm{a}} \pm 1.47$ \\
\hline "n6- pathway" [11] (C20:4/C18:2) & $0.300^{\mathrm{a}} \pm 0.056$ & $0.082^{b} \pm 0.118$ \\
\hline "n3- pathway" [11] (C20:5 + C22:6/C18:3) & $7.99^{\mathrm{a}} \pm 11.4$ & $0.692^{b} \pm 3.26$ \\
\hline Ratio n6/n3 [11] (C18:2 + C20:2 + C20:3 + C20:4/C18:3 + C20:5 + C22:6) & $17.3^{\mathrm{a}} \pm 8.34$ & $18.8^{\mathrm{a}} \pm 6.25$ \\
\hline Ratio C18:0/C16:0 [6] & $0.913^{\mathrm{a}} \pm 0.152$ & $0.311^{b} \pm 0.165$ \\
\hline Ratio C16:1n7/C16:0 [6] & $0.090^{\mathrm{b}} \pm 0.071$ & $0.165^{a} \pm 0.066$ \\
\hline Ratio C18:1n9/C16:0 [6] & $0.938^{b} \pm 0.616$ & $4.03^{\mathrm{a}} \pm 1.47$ \\
\hline Ratio $n 6 / n 3$ [6] (C18:2n6 + C20:3n6 + C20:4n6/C18:3n3 + C22:6n3) & $23.5^{\mathrm{a}} \pm 12.5$ & $20.1^{\mathrm{a}} \pm 7.30$ \\
\hline
\end{tabular}

$\overline{a, b}$ Values within a row concerning object of investigation with different superscripts differ significantly at $P<0.05$ 
Table 5 Crosstab regarding intercorrelations between iron content, total fatty acids and individual fatty acids in the liver tissue of deceased animals

\begin{tabular}{|c|c|c|c|c|c|c|c|c|c|c|c|c|c|c|c|c|c|c|}
\hline & & \multirow[b]{2}{*}{$\mathbb{D}^{\top}$} & \multirow[b]{2}{*}{$\begin{array}{l}\stackrel{T}{\phi} \\
\stackrel{1}{=}\end{array}$} & \multirow[b]{2}{*}{$\stackrel{M}{\vec{\Phi}}$} & \multirow[b]{2}{*}{$\underset{\vec{a}}{\stackrel{\rho}{\vec{b}}}$} & \multirow[b]{2}{*}{ 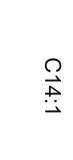 } & \multirow[b]{2}{*}{$\stackrel{\stackrel{\rho}{\sigma}}{\ddot{\theta}}$} & \multirow[b]{2}{*}{$\stackrel{\stackrel{\rho}{\sigma}}{\stackrel{\vec{i}}{ }}$} & \multicolumn{3}{|c|}{ Correlation coefficient $^{a}$} & \multirow[b]{2}{*}{$\begin{array}{l}\stackrel{\Omega}{\overrightarrow{0}} \\
\stackrel{\infty}{\overrightarrow{\vec{\sigma}}} \\
\stackrel{0}{0}\end{array}$} & \multirow[b]{2}{*}{$\begin{array}{l}\stackrel{\rho}{\infty} \\
\stackrel{\infty}{\tilde{N}} \\
\stackrel{\sigma}{\sigma}\end{array}$} & \multirow[b]{2}{*}{$\begin{array}{l}\stackrel{\Omega}{\vec{\infty}} \\
\stackrel{\dot{\omega}}{\omega} \\
\stackrel{\omega}{\omega}\end{array}$} & \multirow[b]{2}{*}{ 尽 } & \multirow[b]{2}{*}{$\begin{array}{l}\text { N } \\
\stackrel{0}{\circ} \\
\stackrel{\Delta}{\sigma}\end{array}$} & \multirow[b]{2}{*}{$\begin{array}{l}\text { N } \\
\text { ơ } \\
\stackrel{\omega}{\omega}\end{array}$} & \multirow[b]{2}{*}{ 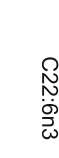 } \\
\hline & & & & & & & & & $\underset{\ddot{\theta}}{\stackrel{?}{\vec{\sigma}}}$ & $\begin{array}{l}\stackrel{\rho}{\phi} \\
\ddot{0}\end{array}$ & 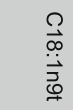 & & & & & & & \\
\hline \multirow{17}{*}{$\begin{array}{l}\frac{0}{2} \\
\frac{1}{\pi} \\
\frac{1}{2} \\
2\end{array}$} & $\mathrm{Fe}$ & & & -0.67 & -0.53 & -0.40 & -0.59 & -0.43 & $-0,38$ & -0.52 & -0.47 & -0.58 & -0.54 & -0.45 & -0.44 & -0.04 & -0.25 & -0.15 \\
\hline & Fe-ff & & & -0.43 & -0.33 & -0.22 & -0.33 & -0.20 & -0.09 & -0.21 & -0.05 & -0.35 & -0.40 & -0.32 & -0.29 & -0.19 & -0.25 & -0.13 \\
\hline & $\sum \mathrm{fa}$ & $<0.01$ & $<0.01$ & & 0.76 & 0.65 & 0.95 & 0.75 & 0.51 & 0.65 & 0.62 & 0.93 & 0.75 & 0.72 & 0.63 & -0.16 & 0.27 & 0.07 \\
\hline & C14:0 & $<0.01$ & $<0.01$ & $<0.01$ & & 0.70 & 0.60 & 0.07 & 0.70 & 0.67 & 0.65 & 0.33 & 0.55 & 0.47 & 0.44 & -0.29 & 0.30 & 0.38 \\
\hline & C14:1 & $<0.01$ & 0.04 & $<0.01$ & $<0.01$ & & 0.58 & 0.92 & 0.02 & 0.24 & 0.37 & 0.79 & 0.20 & 0.25 & 0.41 & 0.27 & 0.01 & -0.14 \\
\hline & C16:0 & $<0.01$ & $<0.01$ & $<0.01$ & $<0.01$ & $<0.01$ & & 0.71 & 0.60 & 0.68 & 0.63 & 0.86 & 0.64 & 0.58 & 0.63 & -0.27 & 0.22 & 0.08 \\
\hline & C16:1 & $<0.01$ & 0.06 & $<0.01$ & 0.52 & $<0.01$ & $<0.01$ & & 0.07 & 0.25 & 0.36 & 0.88 & 0.28 & 0.33 & 0.45 & -0.28 & -0.06 & -0.14 \\
\hline & C17:0 & $<0.01$ & 0.43 & $<0.01$ & $<0.01$ & 0.84 & $<0.01$ & 0.52 & & 0.61 & 0.65 & 0.33 & 0.55 & 0.47 & 0.44 & -0.29 & 0.30 & 0.38 \\
\hline & C18:0 & $<0.01$ & 0.05 & $<0.01$ & $<0.01$ & 0.03 & $<0.01$ & 0.02 & $<0.01$ & & 0.66 & 0.54 & 0.55 & 0.51 & 0.56 & -0.25 & 0.42 & 0.29 \\
\hline & C18:1n9t & $<0.01$ & 0.65 & $<0.01$ & $<0.01$ & $<0.01$ & $<0.01$ & $<0.01$ & $<0.01$ & $<0.01$ & & 0.58 & 0.48 & 0.50 & 0.57 & -0.53 & 0.28 & 0.02 \\
\hline & $\mathrm{C} 18: 1 \mathrm{n} 9 \mathrm{c}$ & $<0.01$ & $<0.01$ & $<0.01$ & $<0.01$ & $<0.01$ & $<0.01$ & $<0.01$ & $<0.01$ & $<0.01$ & $<0.01$ & & 0.51 & 0.53 & 0.63 & -0.30 & 0.15 & -0.05 \\
\hline & $\mathrm{C} 18 \mathrm{an} 6 \mathrm{c}$ & $<0.01$ & $<0.01$ & $<0.01$ & $<0.01$ & 0.06 & $<0.01$ & $<0.01$ & $<0.01$ & $<0.01$ & $<0.01$ & $<0.01$ & & 0.93 & 0.47 & 0.23 & 0.42 & 0.11 \\
\hline & C18:3n3 & $<0.01$ & $<0.01$ & $<0.01$ & $<0.01$ & 0.02 & $<0.01$ & $<0.01$ & $<0.01$ & $<0,01$ & $<0.01$ & $<0.01$ & $<0.01$ & & 0.38 & 0.21 & 0.33 & 0.11 \\
\hline & $\mathrm{C} 20: 1$ & $<0.01$ & $<0.01$ & $<0.01$ & $<0.01$ & $<0.01$ & $<0.01$ & $<0.01$ & $<0.01$ & $<0.01$ & $<0.01$ & $<0.01$ & $<0.01$ & $<0.01$ & & \multirow[t]{2}{*}{-0.37} & 0.39 & -0.03 \\
\hline & $\mathrm{C} 20: 4 \mathrm{n} 6$ & 0.73 & 0.08 & 0.14 & $<0.01$ & 0.01 & 0.01 & $<0.01$ & $<0.01$ & 0.02 & $<0.01$ & $<0.01$ & 0.03 & 0.06 & $<0.01$ & & 0.09 & 0.11 \\
\hline & $\mathrm{C} 20: 5 \mathrm{n} 3$ & 0.02 & 0.02 & 0.01 & $<0.01$ & 0.92 & 0.04 & 0.58 & $<0.01$ & $<0.01$ & 0.01 & 0.18 & $<0.01$ & $<0.01$ & $<0.01$ & 0.41 & & \multirow[t]{2}{*}{0.25} \\
\hline & $\mathrm{C} 22: 6 \mathrm{n} 3$ & 0.18 & 0.29 & 0.55 & $<0.01$ & 0.19 & 0.46 & 0.21 & $<0.01$ & $<0.01$ & 0.87 & 0.67 & 0.30 & 0.33 & 0.75 & 0.34 & 0.02 & \\
\hline
\end{tabular}

a Pearson correlation coefficients - for combination of fatty acids between grey boxes; Spearman correlation coefficients - combination of colourless boxes); correlations: 00-.19 "very weak"; .20-.39 "weak"; .40-.59 "moderate"; .60-.79 "strong"; .80-1.0 "very strong"

was significantly higher in the category $>200-250 \mathrm{~g}$ fat $/ \mathrm{kg}$ DM liver tissue (Fig. 2). With increasing fat content in the liver, the iron contents in liver tissue were lower. When calculating the levels of iron in the liver to the fat-free mass of liver issue, the iron content in absolute terms was higher. The absolute differences, however, were lower. Nevertheless, the iron content in fat-free liver tissue of affected birds in the category $>200-250$ g fat/kg DM liver tissue (Fig. 2) was significantly higher than in livers of dead animals with less than 200 grammes of fat and those with more than 400 grammes of fat.

\section{Discussion}

Hepatic lipidosis in turkeys is a disease that is accompanied by a massive fat accumulation in liver tissue as well as being the cause of high animal losses $[1,2,12,13]$. The disease was described in Canada for the first time [1]. Both, a metabolic or an infectious genesis is suspected, but the exact cause of the disease has not yet been verified $[1,2,12]$, also not in other birds [14]. To date, there are only very few studies which describe the functional characteristics of the turkey liver [15]. Livers of turkeys that died from hepatic lipidosis have not yet been analysed systematically for fat content, fatty acid profile and iron
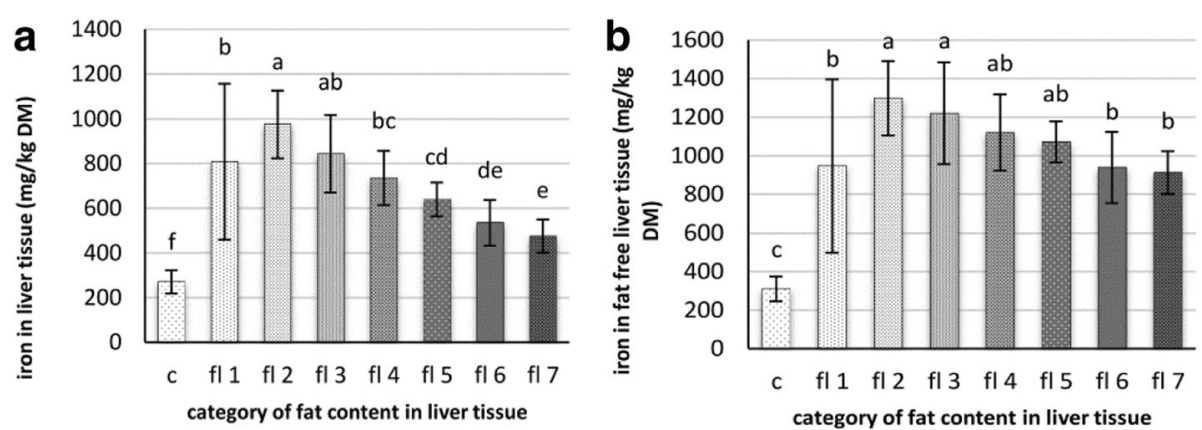

Fig. 2 Mean levels of iron in the liver tissue (a) and iron in the fat free liver tissue (b) as a function of group membership (control [c, $n=16]$ or case [fl1-fl7, $n=85]$ ) or the sum of fatty acids content in the liver (fl $1: \leq 200 \mathrm{~g} / \mathrm{kg} \mathrm{DM}, n=8 ; \mathrm{fl} 2:>200-250 \mathrm{~g} / \mathrm{kg} \mathrm{DM}, n=10 ; \mathrm{fl} 3:>250-300 \mathrm{~g} / \mathrm{kg}$

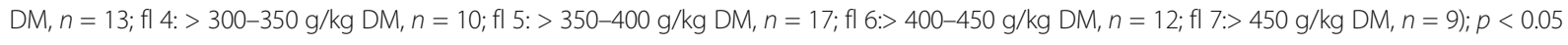


content by classical chemical methods. The comparative analysis of the fatty acid pattern, differences and shifts in the composition of the fatty acids can help to understand the pathogenesis, especially in a comparative consideration to other species $[6,11,16-18]$. In addition, the concentration of specific fatty acids in the liver is a good biomarker for assessing non-alcoholic fatty liver disease (NAFLD) in animal models [19].

In the current study, an increase in liver fat-\% was seen ( 2.8 fold; 2.5 fold concerning the sum of fatty acids). An accumulation of most fatty acids in the liver of animals that died from hepatic lipidosis was detected. Only the contents of arachidonic acid, eicosapentaenoic acid and docosahexaenoic acid were significantly lower.

Palmitic acid is considered to be a toxic fatty acid for the liver [6, 20,21]. In comparison to humans [6], the content of this fatty acid was numerically slightly higher in healthy turkeys $(8.26 \pm 2.57 \mathrm{~g} / \mathrm{kg}$ liver tissue in turkeys versus $5.45 \pm 0.670 \mathrm{~g} / \mathrm{kg}$ liver tissue in humans). In humans [6], the contents in simple steatosis and steatohepatitis are significantly higher. That was also the case in the present study, albeit in livers of the highest fat category, values from humans were not reached (47.6 \pm 4.69 $\mathrm{g} / \mathrm{kg}$ at $>450 \mathrm{~g}$ fat $/ \mathrm{kg}$ liver tissue versus $52.8 \pm 8.03$ in SS and $92.8 \pm 21.0 \mathrm{~g} / \mathrm{kg}$ in NASH liver tissue for C16:0). The situation is similar for oleic acid, the unsaturated product of conversion of palmitic acid [6]. In palmitoleic acid in the highest fat category, however, the concentrations of the fatty acids are comparable to those of people with steatohepatitis $(10.5 \pm 3.29 \mathrm{~g} / \mathrm{kg}$ liver versus $10.9 \pm$ $2.35 \mathrm{~g} / \mathrm{kg}$ liver tissue in people with NASH).

For birds, liver is the main site of fatty acid synthesis $[22,23]$. Storage of large quantities of fat triglycerides in the liver as an energy source is a biological mechanism in migratory birds $[24,25]$. This mechanism is analogous to human medicine. Like migratory birds, humans with an excessive calorie consumption also deposit fat in the liver [24]. Unlike poultry, fatty liver in humans is less adaptable [24]. Nevertheless, it makes sense to take a comparative closer look at the two phenomena. The earliest stage in the disease complex called nonalcoholic fatty liver disease (NAFLD) is hepatic steatosis [19]. In humans, steatosis is defined as a hepatic triglyceride level exceeding $>55.0 \mathrm{mg}$ per $\mathrm{g}$ of liver [24]. In this study, livers of control animals had a fatty acid content of $35.3 \pm 10.3 \mathrm{mg}$ per $\mathrm{g}$ of liver tissue.

Fatty liver in birds occurs whenever the increase in lipogenesis exceeds the capacity for synthesis and secretion of lipoproteins [15]. Physiologically, this occurs naturally under estrogen dominance as a so- called fatty liver hemorrhagic syndrome in laying hens. In turkeys, hepatic steatosis is different and a condition that particularly favours development of hepatic lipidosis has yet to be determined [15]. In humans, the increased supply of free fatty acids to the liver from the diet, from adipose tissue, and through increased de novo lipogenesis all serve to promote hepatic steatosis [24]. About $59 \%$ of hepatic fat is derived from circulating free fatty acids, lower percentages coming from de novo lipogenesis (26\%) and the diet (15\%) [26]. In chickens, the liver is the major site of fatty acid synthesis [22]. During fasting, liver lipid is mobilized rapidly [22]. Fasting reduces lipogenesis and increases lipolysis [22]. In voles (Arvicolinae) fasted for $18 \mathrm{~h}$, increase in liver fat- $\%$ was statistically significant (2-fold) [18].

As described for nonalcoholic steatohepatitis in humans [6], it could also be verified in this study that the ratio of $\mathrm{C} 18: 0 / \mathrm{C} 16: 0$ falls and the ratio of $\mathrm{C} 16: 1 \mathrm{n} 7 /$ $\mathrm{C} 16: 0$ rises. The former is correlated with inflammation and the ballooning of hepatocytes in the liver tissue, the latter with an inflammation of the liver tissue in general [6]. For a detailed assessment of liver disease, the socalled metabonomic biomarker is used as a parameter [19]. Thus, lower concentrations of arachidonic acid, eicosapentaenoic acid and docosahexaenoic acid are good markers. In the present study, these acids were found in lower concentrations in suspicious liver tissue, too.

The iron content in the liver was analysed since infectious and inflammatory diseases may lead to an accumulation of iron in the liver in specific cases [27-30].

On the one hand, significantly higher iron contents in the liver tissue were found in turkeys died from hepatic lipidosis in comparison to healthy animals. On the other hand, it was possible to demonstrate that in animals that had died from hepatic lipidosis, the sum of the fatty acids in the liver showed a negative correlation to the iron content in the liver (PCC: $-0.67 ; p<0.01$ ). In principle, this means that the accumulation of fat in the liver under the condition of hepatic lipidosis is associated with a higher concentration of iron. However, with increasing fat content, the iron concentrations decreased. In healthy poultry, liver contains concentrations of more than $60 \mathrm{mg} / \mathrm{kg}$ iron (equivalent to about 220 $\mathrm{mg} / \mathrm{kg} \mathrm{DM}$ ) in fresh tissue [31]. The control livers of healthy animals therefore had normal iron contents in this study, which should by no means be described as high. Only levels of more than $300 \mathrm{mg} / \mathrm{kg}$ iron in liver tissue may be referred to as high [31]. Tissue injury due to excess iron eventually leads to organ dysfunction [32, 33]. In general, liver damage (hepatic fibrosis, cirrhosis) occurs when liver iron concentration increases to more than 10times the normal level [34]. This means that there was indeed a significant increase in liver iron levels. However, it cannot be assumed that there was liver damage induced only by iron accumulation in liver tissue in this study.

Slight differences in the iron content of the liver tissue can be caused by a different residual blood content alone. However, there are no studies on the residual 
blood content in turkey livers. From studies in rats [35], differences in residual blood contents in the liver tissue of $0.11 \mathrm{~g} / \mathrm{cm}^{3}$ are known. With an estimated iron content of $0.44 \mathrm{mg} / \mathrm{g}$ blood ([36]; values from pigs) this would corresponds to a possible difference in the iron content in liver tissue (with or without bleeding) of 48.4 $\mathrm{mg} / \mathrm{kg}$ liver.

It is still unknown as to what stimulated the accumulation of iron in the liver. Hepcidin is the main regulator of iron homeostasis in vertebrates [28, 37-39]. The liver plays a central role in regulating iron homeostasis because the liver is the main producer of hepcidin as well as being the main iron depot in the body $[7,38,39]$. It is known that both, cytokines and hepcidin, force the iron retention in the spleen, liver and bone marrow macrophages [30, 40]. Normally, the synthesis is induced by systemic iron levels and by inflammatory stimuli $[34,37]$. The liver responds to inflammatory signals originating extrahepatically by increasing the hepcidin level [38]. Infections or stimuli that are likely to induce liver hepcidin expression, reduce serum iron and increase iron accumulation in reticuloendothelial cells [38, 41].

In three cases of hepatic lipidosis among turkey breeder flocks, virus particles similar to parvo- or picornavirus were detected via electron microscopy [2]. In addition, picornavirus RNA was found in the livers of one turkey flock with PCR techniques [2]. In a case report, which refers to the data of this previous study on hepatic lipidosis, antibodies against Avian Encephalomyelitis Virus and genome fractions of Turkey Viral Hepatitis Virus were found [4]. In fact, it cannot be ruled out that a specific infectious agent causes the iron accumulation in the liver.

Iron accumulation also occurs in other noninfectious disorders of the liver [7, 39]. The expression of hepcidin, for example, is also stimulated by adipokines [40, 42]. Hepcidin levels were significantly higher in obese children with NAFLD than in those without NAFLD [43]. According to the present study, therefore, changes in the hepcidin regulation would be possible but should be the focus of future investigations.

\section{Conclusions}

In summary, there are two aspects that have to be underlined: On the one hand, the development of a fatal fatty liver disease, on the other hand the changes in iron concentrations in the liver. In the genesis of NASH in humans "two hits" arise [44, 45]. In a first stage there is a hepatic steatosis. In a second stage, proinflammatory cytokines lead to oxidative stress and liver damage [44]. It can be assumed that diet and feeding cause a certain predisposition to a fatty liver. As an attendant characteristic of an infection, there is a cytokine mediated reduced feed intake [46]. This may foster the development of fatty liver disease in turkeys, too. By infection-related release of inflammatory mediators and a derailment of iron metabolism further damage of the liver tissue occurs ultimately leading to the death of affected animals. This could be also an explanation for the high animal losses in the case of hepatic lipidosis in turkeys.

In general, the turkey could thus serve as a good animal model for certain metabolic and infections related metabolic problems in human medicine because the animal is sensitive to various triggers and shows typical mechanisms of liver disease.

\section{Abbreviations}

DM: Dry matter; fl: Fatty acid class; NAFLD: Nonalcoholic fatty liver disease; NASH: Nonalcoholic steatohepatitis; SS: Simple steatosis

\section{Acknowledgements \\ We would like to thank the farmers who provided the animals for taking samples through the veterinarians. We would like to thank Jörg Senkpiel, Katrin von dem Hagen and Ilona Schoan for the support in analysing the samples and Frances Sherwood-Brock for editing the manuscript to ensure correct English.}

\section{Funding}

There was no funding of the study.

\section{Availability of data and materials}

The datasets used and/or analysed during the current study are available from the corresponding author on reasonable request.

\section{Authors' contributions}

CV and DR were the initiators of the idea. CV designed the study. CV and DR visited the farms. $A E, C L, H M, K D$, SM took the samples. $C V$ and $L M$ made the analyses. CV did the statistics. CV wrote the paper. All authors read and approved the final manuscript.

\section{Competing interests}

The authors declare that they have no competing interests.

Consent for publication

Not applicable.

\section{Ethics approval and consent to participate}

The investigations were not part of an animal experiment. Interventions were carried out only on turkeys died on hepatic lipidosis or slaughtered animals. So, this study was not based on an animal experiment requiring a notification or an approval according to the Animal Protection Act.

\section{Publisher's Note}

Springer Nature remains neutral with regard to jurisdictional claims in published maps and institutional affiliations.

\footnotetext{
Author details

${ }^{1}$ Institute for Animal Nutrition, University of Veterinary Medicine Hannover, Foundation, Bischofsholer Damm 15, D-30173 Hannover, Germany. ${ }^{2}$ Heidemark GmbH, Veterinärlabor, Jakob-Uffrecht-Str. 20, D-39340 Haldensleben, Germany. ${ }^{3}$ Tierarztpraxis Dr. A. Engels, Gut Hacheney 2-5, D-59199 Bönen-Lenningsen, Germany. ${ }^{4}$ Tierärztliche Gemeinschaftspraxis Dres. Windhaus \& Hemme, An der Ohe 1, D-49377 Vechta, Germany. ${ }^{5}$ Tierarztpraxis an der Güterstraße, Güterstraße 7, D-46499 Hamminkeln, Germany. ${ }^{6}$ Praxis am Bergweg, Bergweg 20, D-49393 Lohne (Oldenburg), Germany. ${ }^{7}$ Institut für Tierpathologie, Schönhauser Str. 62, D-13127 Berlin, Germany. ${ }^{8}$ Elanco Animal Health $\mathrm{GmbH}$, Werner-Reimers-Str. 2-4, Bad Homburg D-61352, Germany.
} 


\section{Received: 16 February 2017 Accepted: 11 May 2017}

\section{Published online: 30 May 2017}

\section{References}

1. Gazdzinski P, Squires E, Julian R. Hepatic lipidosis in turkeys. Avian Dis. 1994; 38:379-84.

2. Popp C, Hauck R, Vahlenkamp T, Lüschow D, Kershaw O, Hoferer M, Hafez HM. Liver pathology associated with increased mortality in turkey breeder and meat turkey flocks. Avian Dis. 2014;58:478-81.

3. Tufarelli V, Bozzo G, Perillo A, Laudadio V. Effects of feeding different lipid sources on hepatic histopathology features and growth traits of broiler chickens. Acta Histochem. 2015;117:780-3.

4. Visscher C, Günther R, Engels A, Leibfacher C, Radko D. Case report: hepatic lipidosis in fattening turkeys. Proceedings of the Society of Comparitive Veterinary Nutrition 2015, accepeted.

5. Kleiner DE, Brunt EM, Van Natta M, Behling C, Contos MJ, Cummings OW, Ferrell LD, Liu YC, Torbenson MS, Unalp-Arida A, et al. Design and validation of a histological scoring system for nonalcoholic fatty liver disease. Hepatology. 2005;41:1313-21.

6. Yamada K, Mizukoshi E, Sunagozaka H, Arai K, Yamashita T, Takeshita Y, Misu H, Takamura T, Kitamura S, Zen Y, et al. Characteristics of hepatic fatty acid compositions in patients with nonalcoholic steatohepatitis. Liver Int. 2015;35:582-90.

7. Pietrangelo A. Iron and the liver. Liver Int. 2016:36:116-23.

8. Naumann C, Bassler R. Methoden der landwirtschaftlichen Forschungs-und Untersuchungsanstalt, Biochemische Untersuchung von Futtermitteln. Methodenbuch III (einschließlich der achten Ergänzungen). Darmstadt: VDLUFA; 2012

9. Vervuert I, Coenen M, Watermulder E. Metabolic responses to oral tryptophan supplementation before exercise in horses. J Anim Physiol Anim Nutr. 2005;89:140-5.

10. Lepage G, Roy CC. Direct transesterification of all classes of lipids in a onestep reaction. J Lipid Res. 1986;27:114-20.

11. Wang XH, Li CY, Muhammad I, Zhang XY. Fatty acid composition in serum correlates with that in the liver and non-alcoholic fatty liver disease activity scores in mice fed a high-fat diet. Environ Toxicol Pharmacol. 2016:44:140-50.

12. Aziz T. Hepatic lipidosis in turkeys. 2009.

13. Gallazzi D, Manarolla G, Rampin T, Saita M, Sironi G. Hepatic lipidosis in turkeys: beyond the current pathogenetic hypothesis. Western Poultry Las Vegas: Disease Conference; 2007.

14. Nemeth N, Gonzalez-Astudillo V, Oesterle P, Howerth E. A 5-Year Retrospective Review of Avian Diseases Diagnosed at the Department of Pathology, University of Georgia. J Comp Pathol. 2016;155:105-20.

15. Hunigen H, Mainzer K, Hirschberg RM, Custodis P, Gemeinhardt O, Al Masri S, Richardson KC, Hafez HM, Plendl J. Structure and age-dependent development of the turkey liver: a comparative study of a highly selected meat-type and a wild-type turkey line. Poult Sci. 2016;95:901-11.

16. Walle $P$, Takkunen $M$, Mannisto V, Vaittinen $M$, Lankinen $M$, Karja $V$, Kakela $P$, Agren J, Tiainen M, Schwab U, et al. Fatty acid metabolism is altered in non-alcoholic steatohepatitis independent of obesity. Metab Clin Exp. 2016;65:655-66.

17. Takahashi Y, Soejima Y, Fukusato T. Animal models of nonalcoholic fatty liver disease/nonalcoholic steatohepatitis. World J Gastroenterol. 2012;18:2300-8.

18. Mustonen A-M, Käkelä R, Halonen T, Kärjä V, Vartiainen E, Nieminen P. Fatty acid mobilization in voles-Model species for rapid fasting response and fatty liver. Comp Biochem Physiol A Mol Integr Physiol. 2012;163:152-60.

19. Willebrords J, Pereira IV, Maes M, Crespo Yanguas S, Colle I, Van Den Bossche B, Da Silva TC, de Oliveira CP, Andraus W, Alves VA, et al. Strategies, models and biomarkers in experimental non-alcoholic fatty liver disease research. Prog Lipid Res. 2015;59:106-25.

20. Malhi H, Gores GJ. Molecular Mechanisms of Lipotoxicity in Nonalcoholic Fatty Liver Disease. Semin Liver Dis. 2008;28:360-9.

21. Mota M, Banini BA, Cazanave SC, Sanyal AJ. Molecular mechanisms of lipotoxicity and glucotoxicity in nonalcoholic fatty liver disease. Metab Clin Exp. 2016;65:1049-61.

22. Scanes CG, Braun E. Avian metabolism: its control and evolution. Front Biol. 2013:8:134-59.

23. Leclercq B. Adipose-Tissue Metabolism and Its Control in Birds. Poult Sci. 1984;63:2044-54
24. Cohen JC, Horton JD, Hobbs HH. Human fatty liver disease: old questions and new insights. Science. 2011;332:1519-23.

25. Lindstrom A, Piersma T. Mass Changes in Migrating Birds - the Evidence for Fat and Protein Storage Reexamined. Ibis. 1993;135:70-8.

26. Donnelly KL, Smith Cl, Schwarzenberg SJ, Jessurun J, Boldt MD, Parks EJ. Sources of fatty acids stored in liver and secreted via lipoproteins in patients with nonalcoholic fatty liver disease. J Clin Invest. 2005;115:1343-51.

27. Tizard IR. Veterinary Immunology. 9th ed. Amsterdam: Elsevier Medical; 2013

28. Girelli D, Nemeth E, Swinkels DW. Hepcidin in the diagnosis of iron disorders. Blood. 2016:127:2809-13.

29. Farinati F, Cardin R, De Maria N, Della Libera G, Marafin C, Lecis E, Burra P, Floreani A, Cecchetto A, Naccarato R. Iron storage, lipid peroxidation and glutathione turnover in chronic anti-HCV positive hepatitis. J Hepatol. 1995:22:449-56

30. Cassat JE, Skaar EP. Iron in Infection and Immunity. Cell Host Microbe. 2013:13:510-20.

31. Puls R. Mineral levels in animal health. Diagnostic data. Clearbrock BC: Sherpa International; 1988.

32. Handa P, Morgan-Stevenson V, Maliken BD, Nelson JE, Washington S, Westerman M, Yeh MM, Kowdley KV. Iron overload results in hepatic oxidative stress, immune cell activation, and hepatocellular ballooning injury, leading to nonalcoholic steatohepatitis in genetically obese mice. Am J Physiol Gastrointest Liver Physiol. 2016;310:G117-27.

33. Tsuchiya H, Ebata Y, Sakabe T, Hama S, Kogure K, Shiota G. High-fat, highfructose diet induces hepatic iron overload via a hepcidin-independent mechanism prior to the onset of liver steatosis and insulin resistance in mice. Metab Clin Exp. 2013;62:62-9.

34. Ganz T, Nemeth E. Regulation of iron acquisition and iron distribution in mammals. Biochim Biophys Acta. 2006;1763:690-9.

35. Oeff K, König A. Das Blutvolumen einiger Rattenorgane und ihre Restblutmenge nach Entbluten bzw. Durchspülung. Bestimmung mit P 32-markierten Erythrocyten. Naunyn Schmiedeberg's Arch Pharmacol. 1955;226:98-102.

36. OELLINGRATH IM, SLINDE E. Color, pigment and iron content of meat loaves with blood, blood emulsion, or mechanically deboned meat added. J Food Sci. 1985:50:1551-5.

37. Michels K, Nemeth E, Ganz T, Mehrad B. Hepcidin and Host Defense against Infectious Diseases. Plos Pathog. 2015;11(8). doi:10.1371/journal.ppat. 1004998.

38. Drakesmith $\mathrm{H}$, Prentice AM. Hepcidin and the iron-infection axis. Science. 2012:338:768-72

39. De Domenico I, Ward DM, Kaplan J. Regulation of iron acquisition and storage: consequences for iron-linked disorders. Nat Rev Mol Cell Biol. 2008;9:72-81.

40. Feldman A, Aigner E, Weghuber D, Paulmichl K. The Potential Role of Iron and Copper in Pediatric Obesity and Nonalcoholic Fatty Liver Disease. Biomed Res Int. 2015;287401. doi:10.1155/2015/287401.

41. Wessling-Resnick M. Iron Homeostasis and the Inflammatory Response. Annu Rev Nutr. 2010;30:105-22.

42. Datz C, Felder TK, Niederseer D, Aigner E. Iron homeostasis in the Metabolic Syndrome. Eur J Clin Investig. 2013;43:215-24

43. Demircioglu F, Gorunmez G, Dagistan E, Goksugur SB, Bekdas M, Tosun M, Kizildag B, Kismet E. Serum hepcidin levels and iron metabolism in obese children with and without fatty liver: case-control study. Eur J Pediatr. 2014;173:947-51.

44. Suzuki-Kemuriyama N, Matsuzaka T, Kuba M, Ohno H, Han S, Takeuchi Y, Isaka M, Kobayashi K, Iwasaki H, Yatoh S, et al. Different Effects of Eicosapentaenoic and Docosahexaenoic Acids on Atherogenic High-Fat Diet-Induced Non-Alcoholic Fatty Liver Disease in Mice. Plos One. 2016; 11(6):e0157580. doi:10.1371/journal.pone.0157580.

45. Day CP, James OFW. Steatohepatitis: A tale of two "hits"? Gastroenterology. 1998;114:842-5.

46. Sandberg FB, Emmans GC, Kyriazakis I. A model for predicting feed intake of growing animals during exposure to pathogens. J Anim Sci. 2006:84:1552-66. 